\title{
Metal ions and degenerative diseases
}

\author{
Liliana Quintanar ${ }^{1} \cdot$ Mi Hee Lim $^{2}$
}

Published online: 23 November 2019

(c) Society for Biological Inorganic Chemistry (SBIC) 2019

\section{Introductory note}

As life expectancy of human beings has increased, so has the incidence of degenerative diseases with aging as an important risk factor. Alzheimer's disease (AD) affects approximately 47 million people worldwide, while Parkinson's disease (PD) is the second most common neurodegenerative disorder. While these neurodegenerative diseases have a multifactorial etiology, in both cases, protein misfolding and accumulation of amyloid aggregates in the brain are observed. Another amyloid deposition pathology is type 2 diabetes, a chronic degenerative disease affecting almost 400 million people worldwide. Metal ions have been implicated in these and other degenerative diseases, as several of the proteins undergoing amyloid aggregation have been identified as metal-binding proteins. Key examples include $\alpha$-synuclein, a Cu-binding protein that constitutes the main component in Lewy bodies in PD, and the amyloid- $\beta$ peptide $(\mathrm{A} \beta)$ that accumulates, along with $\mathrm{Cu}, \mathrm{Fe}$ and $\mathrm{Zn}$, in $\mathrm{AD}$ plaques. While the physiological function of these metal-binding proteins is not well understood, the role of the metal-protein interactions in the etiology of each disease is even less clear. The metals implicated include essential metal ions, such as $\mathrm{Cu}, \mathrm{Zn}, \mathrm{Fe}$ and $\mathrm{Mn}$, for which their homeostasis may be perturbed at a late age. Additionally, exposure to xenobiotic metals, such as $\mathrm{Pb}, \mathrm{Hg}$, and $\mathrm{Cd}$, and metalloids, such as As, has also been associated with toxicity and neurodegeneration [1].

The involvement of metal-binding proteins in degenerative diseases has sparked active research by bioinorganic

\footnotetext{
Liliana Quintanar

lilianaq@cinvestav.mx

Mi Hee Lim

miheelim@kaist.ac.kr

1 Department of Chemistry, Centro de Investigación y de Estudios Avanzados (Cinvestav), Mexico City, Mexico

2 Department of Chemistry, Korea Advanced Institute of Science and Technology (KAIST), Daejeon, Republic of Korea
}

chemists to elucidate the nature of these metal-protein interactions, to understand the impact of metal binding in the folding of the protein and its ability to form oligomeric species and aggregates, and to study the redox properties of the metal-protein complexes and their impact in oxidative stress. A deep understanding of the bioinorganic chemistry of metal-protein interactions associated with degenerative diseases can pave the road for the design of multifunctional molecules with therapeutic potential, as it has become clear in the case of $\mathrm{AD}$ [2]. In this issue, we have gathered a collection of mini-reviews, commentaries, and papers that summarize and illustrate the most recent advances in the biological inorganic chemistry research of neurodegenerative diseases, an area also termed metalloneurochemistry or metalloneuroscience.

This issue begins with a mini-review by Acevedo et al. [3], where the roles of redox-active metal ions, $\mathrm{Cu}$ and $\mathrm{Fe}$, in neurodegenerative diseases, such as $\mathrm{AD}, \mathrm{PD}$ and amyotrophic lateral sclerosis, are discussed. Indeed, the homeostasis of these two essential metal ions is affected, and the authors summarize the results of preclinical and clinical studies of some metal chelators that target the brain levels of metal ions. This discussion is continued in the minireview by Yang et al. [4], which examines the feasibility of rebalancing metal ion homeostasis as a therapeutic strategy for $\mathrm{AD}$, using metal chelators, $\mathrm{A} \beta$ aggregation inhibitors, and other multifunctional agents targeting AD-related proteases. The authors conclude that the development of new pharmacological agents for AD requires the elucidation of the precise mechanisms of metal ion homeostasis. The functional role of the metal-binding proteins involved in most neurodegenerative diseases is not clear. This is the case for $\mathrm{A} \beta$ peptide and the amyloid precursor protein (APP), a membrane protein that generates $A \beta$ upon proteolytic processing. Both A $\beta$ and APP are metal-binding proteins, and the commentary by Bailey and Kosman [5] specifically addresses the important question of their physiological function. While there is a positive correlation between brain iron content and $\mathrm{A} \beta$ plaque formation in $\mathrm{AD}$, our understanding of how these two variables are related is limited. This commentary 
discusses a potential role of APP and its secretase-originated products in modulating Fe trafficking into the brain, providing a fresh outlook to investigate Fe-related neuropathology. On the other hand, the mini-review by Lutsenko et al. [6] summarizes the mechanisms that maintain homeostasis of copper, another redox-active metal ion that is essential for development and function in the brain. Menkes and Wilson diseases are genetic disorders associated with the $\mathrm{Cu}$ transporters, ATP7A and ATP7B, respectively. In both diseases, brain $\mathrm{Cu}$ homeostasis is severely affected. This review discusses the important role of $\mathrm{Cu}$ in catecholamine metabolism in noradrenergic neurons, where $\mathrm{Cu}$ is essential for the conversion of dopamine to norepinephrine by the $\mathrm{Cu}$-dependent enzyme dopamine $\beta$-hydroxylase.

The early discovery that the AD-related $\mathrm{A} \beta$ is a metalbinding peptide sparked intensive research activity in this area, as it becomes evident in this issue. The mini-review by Wärmländer et al. [7] summarizes the metal-binding properties of $A \beta$ in the presence of biomembranes, as this aspect becomes relevant in the proposed mechanisms for its cell toxicity. While $\mathrm{A} \beta$ plaques are present in the $\mathrm{AD}$ brain, the latest research associates the neurotoxicity of this peptide with its oligomeric forms, which can interact with cell membranes. Hence, it is important to study how metal binding to $\mathrm{A} \beta$ may impact its ability to form oligomers and aggregates. This question has been extensively addressed for the case of $\mathrm{Cu}(\mathrm{II})$, as reviewed by Weibull et al. [8]. Protein oligomerization and aggregation are highly complex biophysical phenomena that pose several experimental challenges for their study. Not surprisingly, the effect of metal ions, such as $\mathrm{Cu}(\mathrm{II})$, on the aggregation of $\mathrm{A} \beta$ has been controversial. Weibull et al. provides a detailed account of this topic, highlighting some of the lessons learned that will certainly be helpful to study other systems. Another extensively studied aspect of $\mathrm{Cu}-\mathrm{A} \beta$ interaction is the redox activity of the metal-peptide complex. The original paper by Vázquez et al. [9] presents a method to quantify nanomolar amounts of dityrosine-bridged dimers of $A \beta$, a species proposed to form upon the incubation of the peptide with $\mathrm{Cu}$ and hydrogen peroxide. Their detection method allows the evaluation of the role of dityrosine-linked species in the aggregation mechanism of $A \beta$, and how it is impacted by molecules with anti-AD potential. Another original paper addressing the redox activity of a copper-peptide complex is that of Cukierman et al. [10], where the impact of a group of aroylhydrazones in the metal-catalyzed oxidation of a prion protein fragment is evaluated. The prion protein $(\mathrm{PrP})$ is associated with a group of transmissible neurodegenerative disorders that include Creutzfeldt-Jakob disease. Although the incidence of these disorders is quite low, as compared to that of $\mathrm{AD}$ or $\mathrm{PD}$, understanding the nature of the $\mathrm{Cu}-\mathrm{PrP}$ interaction would also be relevant to synaptic processes affected in $\mathrm{AD}$ [1]. Beyond $\mathrm{AD}$ and prion diseases, type 2 diabetes
(T2D) is a chronic degenerative disorder where $\mathrm{Cu}$-protein interactions have also been implicated. The mini-review by $\mathrm{Pal}$ et al. [11] compares the nature of the $\mathrm{Cu}$-binding sites in $\mathrm{A} \beta$ with those of amylin, a peptide associated with T2D. When a patient is diagnosed with this metabolic chronic disorder, amyloid fibrils of amylin, also known as islet amyloid polypeptide (IAPP), are already deposited in their pancreas. IAPP is a metal-binding peptide hormone that is normally co-released with insulin from pancreatic $\beta$-cells. While its physiological function is not known, its metal-binding properties have gained recent attention by bioinorganic chemists. This mini-review provides a comparison of IAPP and A $\beta$, their Cu-binding properties and redox activity, and it will certainly spark even more interest in the biological inorganic chemistry of diabetes.

The next two manuscripts in this issue relate to the Parkinson protein: $\alpha$-synuclein $(\alpha S)$. Its amyloid aggregation is responsible for the formation of Lewy bodies in the substantia nigra pars compacta of PD patients. The metal-binding properties of $\alpha \mathrm{S}$ have been extensively studied, while the interplay between metal coordination and posttranslational modifications of this presynaptic protein is an active and current research topic. The original paper by Abeyawardhane et al. [12] reports the use of photochemical crosslinking of unmodified proteins (PICUP) to evaluate metal-induced structural alterations of $\alpha \mathrm{S}$ upon coordination of $\mathrm{Cu}$ and/ or $\mathrm{Fe}$ ions, which can impact the formation of dityrosinelinked species, involved in protein aggregation. Their work points to a potential application of PICUP methodology to study how metal ions modulate the structural dynamics of a protein and its posttranslational modifications. On the other hand, the original paper by González et al. [13] illustrates how the binding of tetrapyrrolic compounds to $\alpha \mathrm{S}$ can modulate its amyloid aggregation. Using a combination of bioinorganic chemistry, biophysics and cell biology tools, the authors find a direct correlation between the interaction profiles of phthalocyanines and porphyrins with $\alpha \mathrm{S}$, their modulatory effects in the amyloid aggregation of the protein, and $\alpha \mathrm{S}$ cell toxicity.

Finally, the last three manuscripts in this issue relate to the neurotoxicity of the xenobiotic metals and metalloids. The commentary by Exley and Mold [14] discusses the potential neurotoxicity of aluminum, although further research is needed to establish a direct link between $\mathrm{Al}$ exposure and neurodegenerative diseases. The mini-review by Chin-Chan et al. [15] discusses the impact of exposure to $\mathrm{Pb}$ in AD-related features, such as aggregation of $\mathrm{A} \beta$ and tau phosphorylation; it argues for a potential risk of $\mathrm{AD}$ development in children populations that are chronically exposed to this toxic metal. Indeed, the human brain is the most susceptible during neurodevelopment, and $\mathrm{Pb}$ is known to cause irreversible neuronal damage at early ages. Similarly, exposure to the metalloid As can also alter cognitive 
function during development through different mechanisms, as discussed by Garza-Lombó et al. [16] in the last minireview of this issue.

We hope the readers will enjoy this diverse collection of manuscripts that illustrate the wide range of facets that the biological inorganic chemistry of degenerative diseases may cover. Understanding the role of metal ions in these diseases to pave the road for the design of molecules with therapeutic potential is a major goal that requires the contribution of different fields, including biophysics, pharmacology, cell biology, genetics, and neuroscience, among others. We would like to thank all authors for their contributions to this special issue, which hopes to inspire young biological inorganic chemists to join this fascinating research field.

Guest Editors:

Liliana Quintanar

Cinvestav, Mexico

Mi Hee Lim

KAIST, Korea

\section{References}

1. Garza-Lombo C, Posadas Y, Quintanar L, Gonsebatt ME, Franco R (2018) Antioxid Redox Signal 28:1669-1703

2. Savelieff MG, Nam G, Kang J, Lee HJ, Lee M, Lim MH (2019) Chem Rev 119:1221-1322

3. Acevedo K, Masaldan S, Opazo CM, Bush AI (2019) J Biol Inorg Chem. https://doi.org/10.1007/s00775-019-01731-9

4. Yang G-J, Liu H, Ma D-L, Leung C-H (2019) J Biol Inorg Chem. https://doi.org/10.1007/s00775-019-01712-y

5. Bailey DK, Kosman DJ (2019) J Biol Inorg Chem. https://doi. org/10.1007/s00775-019-01684-z
6. Lutsenko S, Washington-Hughes C, Ralle M, Schmidt K (2019) J Biol Inorg Chem. https://doi.org/10.1007/s00775-019-01737-3

7. Wärmländer SKTS, Österlund N, Wallin C, Wu J, Luo J, Tiiman A, Jarvet J, Gräslund A (2019) J Biol Inorg Chem. https://doi. org/10.1007/s00775-019-01723-9

8. Weibull MGM, Simonsen S, Oksbjerg CR, Tiwari MK, Hemmingsen L (2019) J Biol Inorg Chem. https://doi.org/10.1007/s0077 5-019-01727-5

9. Vázquez G, Caballero AB, Kokinda J, Hijano A, Sabaté R, Gamez P (2019) J Biol Inorg Chem. https://doi.org/10.1007/s00775-01901734-6

10. Cukierman DS, Bodnár N, Evangelista BN, Nagy L, Kállay C, Rey NA (2019) J Biol Inorg Chem. https://doi.org/10.1007/s0077 5-019-01700-2

11. Pal I, Roy M, Dey SG (2019) J Biol Inorg Chem. https://doi. org/10.1007/s00775-019-01724-8

12. Abeyawardhane DL, Curry AM, Forney AK, Roberts JW, Lucas HR (2019) J Biol Inorg Chem. https://doi.org/10.1007/s0077 5-019-01738-2

13. González N, Gentile I, Garro HA, Delgado-Ocaña S, Ramunno CF, Buratti FA, Griesinger C, Fernández CO (2019) J Biol Inorg Chem. https://doi.org/10.1007/s00775-019-01711-z

14. Exley C, Mold MJ (2019) J Biol Inorg Chem. https://doi. org/10.1007/s00775-019-01710-0

15. Chin-Chan M, Cobos-Puc L, Alvarado-Cruz I, Bayar M, Ermolaeva M (2019) J Biol Inorg Chem. https://doi.org/10.1007/s0077 5-019-01739-1

16. Garza-Lombó C, Pappa A, Panayiotidis MI, Gonsebatt ME, Franco R (2019) J Biol Inorg Chem. https://doi.org/10.1007/s0077 5-019-01740-8

Publisher's Note Springer Nature remains neutral with regard to jurisdictional claims in published maps and institutional affiliations. 